\title{
Introduction to the Special Issue on the 2011 Tohoku Earthquake and Tsunami
}

\author{
by T. Lay, Y. Fujii, E. Geist, K. Koketsu, J. Rubinstein, T. Sagiya, and M. Simons
}

The 11 March 2011 Tohoku earthquake (05:46:24 UTC) involved a massive rupture of the plate-boundary fault along which the Pacific plate thrusts under northeastern Honshu, Japan. It was the fourth-largest recorded earthquake, with seismic-moment estimates of $3-5 \times 10^{22} \mathrm{~N} \cdot \mathrm{m}\left(M_{\mathrm{w}} 9.0\right)$. The event produced widespread strong ground shaking in northern Honshu; in some locations ground accelerations exceeded $2 g$. Rupture extended $\sim 200 \mathrm{~km}$ along dip, spanning the entire width of the seismogenic zone from the Japan trench to below the Honshu coastline, and the aftershock-zone length extended $\sim 500 \mathrm{~km}$ along strike of the subduction zone. The average fault slip over the entire rupture area was $\sim 10 \mathrm{~m}$, but some estimates indicate $\sim 25 \mathrm{~m}$ of slip located around the hypocentral region and extraordinary slip of up to $60-80 \mathrm{~m}$ in the shallow megathrust extending to the trench. The faultinggenerated seafloor deformation produced a devastating tsunami that resulted in 5-10-km inundation of the coastal plains, runup of up to $40 \mathrm{~m}$ along the Sanriku coastline, and catastrophic failure of the backup power systems at the Fukushima Daiichi nuclear power station, which precipitated a reactor meltdown and radiation release. About 18,131 lives appear to have been lost, 2829 people are still missing, and 6194 people were injured (as reported 28 September 2012 by the Fire and Disaster Management Agency of Japan) and over a half million were displaced, mainly due to the tsunami impact on coastal towns, where tsunami heights significantly exceeded harbor tsunami walls and coastal berms.

The 2011 Tohoku event is the largest earthquake known to have struck Japan, a country having a very long documented earthquake history. Seismic-hazard assessments based on instrumentally observed and historically documented events led most researchers to expect earthquakes no larger than about $M 8.5$ in the region, thus the $M_{\mathrm{w}} 9.0$ event and huge tsunami caught many by surprise. Large subduction zone earthquakes in the past 120 years include huge tsunami-generating events off the coast of Sanriku in 1896 $\left(M_{\mathrm{w}} \sim 8.2-8.5\right.$ shallow megathrust-earthquake and tsunami) and 1933 ( $M_{\mathrm{w}} \sim 8.4$ trench slope normal-fault rupture), and several large events deeper on the plate-boundary megathrust fault offshore of Miyagi and Fukushima prefectures $\left(M_{\mathrm{w}} \sim\right.$ 7.7-8.2). Earlier historic events that produced substantial tsunamis along northeastern Honshu occurred off Sanriku in 1611, off Boso in 1677, and off Sendai in 869. The 869 Jogan event produced a large inundation on the Sendai plain that had been documented previously, but the 2011 Tohoku event was distinctive in producing both comparable inundation of Sendai as well as runup along the Sanriku coast similar to that for the 1896 tsunami earthquake. Critical decisions about protective measures, such as heights of tsunami walls, had been based on maximum tsunami expectations guided by the historical record, but this proved inadequate when the 2011 event ruptured the entire megathrust width, including re-rupturing several regions, which had experienced smaller events during the past century. This rare style of rupture had not been considered in most hazard scenarios.

Geodetic observations made over the preceding decade had clearly documented strain accumulation in the Honshu crust consistent with frictional locking of the down-dip portion of the plate boundary, but the offshore extent of the locked region and associated seismogenic potential of the shallow megathrust was uncertain. A new generation of offshore seafloor Global Positioning Systems (GPS) measurements was underway, but these had not yet provided clear indications of the shallow extent of fault locking and strain accumulation when the 2011 event took place.

The 2011 earthquake is the best instrumentally recorded great earthquake, with extensive global seismic recordings, trans-Pacific tsunami-buoy recordings, high-rate (1 sample/sec) solutions from over 1200 GPS stations in Japan, hundreds of strong-motion recordings from the K-NET and KiK-net borehole and surface networks, hundreds of regional short-period seismograms from Hi-net borehole seismic sensors, regional GPS-tsunami gauge, wave and tide gauge, and ocean-bottom pressure-sensor recordings of the seafloor and ocean-surface deformations associated with the earthquake. Hundreds of papers have already been published on the earthquake and this special issue contains a broad cross section of 30 detailed investigations and synthesis of the rupture process, seismic radiation, geodetic deformations, tsunami waves, perturbations of the crustal medium, and regional and remote aftershocks produced by the 2011 Tohoku event.

It is now widely recognized that seismic-hazard assessments based on historical observations can underestimate the largest possible earthquake in a given region. This presents great challenges for defining the likelihood of the largest credible event that may threaten a region, and various methods, for example, ones based on combinations of seismicity catalogs and plate-tectonic configurations and long-term motions, have been explored to provide improved assessment of the hazard posed by rare, very large events exceeding historical observations.

Kagan and Jackson (2013) consider the maximum-size earthquake expected along the Japan subduction zone based 
on the seismic-moment-conservation principle, in which the total moment rate for a subduction zone is estimated from geologic or geodetic deformation rates. With evidence that different subduction zones have indistinguishable statistical parameters ( $b$-values and upper magnitude parameters), they argue that as a group the corner magnitude of subduction zones should be well above magnitude 9 , and that this is appropriate for the Tohoku region. From this perspective, the size of the Tohoku event and the occurrence of five global events of magnitude 9 or larger during the 120-year-long seismological record are not surprising. The expected return time for such events along Japan is further estimated as about $300-400$ years, and for a 382-year recurrence time there is about a 5\% chance of a time interval of 1142 years, as corresponds to the period from the 869 Jogan event to 2011.

There was a pronounced foreshock sequence in the month prior to the 2011 rupture, and indications of slow-slip events near the eventual hypocenter. Kawamura et al. (2013) address the regional seismicity patterns around the Japan subduction zone prior to the 2011 rupture using a patterninformatics approach extended to seek space-time variations in precursory hotspots of seismic-rate changes. They find that increased rates of activity near the coastal margin appear to have migrated toward the 2011 epicenter since about 2000 , and infer that this reflects a preparatory process related to the buildup of stress to failure in 2011.

In the several decades prior to the Tohoku earthquake, global and regional seismic, geodetic, and tsunami recording systems were extensively deployed in Japan as well as globally. These yielded unprecedented data sets for analysis of the mainshock-rupture processes. Kubo and Kakehi (2013) perform joint inversion of teleseismic body waves and onshore and offshore static ground displacements from geodetic sensors to invert for the space-time distribution of slip. Long subfault slip durations of $100 \mathrm{~s}$ and a rupture velocity of $2.0 \mathrm{~km} / \mathrm{s}$ are estimated for a rupture with a 150 -s total duration and peak slip of $43 \mathrm{~m}$ in the shallow part of the fault model seaward of the hypocenter. The overall region with significant slip of larger than $4 \mathrm{~m}$ extends about $300 \mathrm{~km}$ along the trench axis from about $36.5^{\circ} \mathrm{N}$ to $39.3^{\circ} \mathrm{N}$.

Yue and Lay (2013) jointly invert teleseismic $P$ waves and short-arc Rayleigh-wave (R1) source-time functions with high-rate-GPS (hr-GPS) data from regional stations in Japan and offshore ocean-bottom static displacements for the slip space-time history of the rupture. They explore the relative resolution provided by each data type, finding some complementary intrinsic resolution that motivates joint inversion. Subfault source durations of up to $55 \mathrm{~s}$ are allowed, with rupture velocity varying from 1.5 to $2.5 \mathrm{~km} / \mathrm{s}$. Normal mode summation was used for modeling the complete ground motions of the hr-GPS recordings. The combined inversion has peak slip of up to $60 \mathrm{~m}$ near the trench and about $25 \mathrm{~m}$ near the hypocenter, with the large-slip $(>10 \mathrm{~m})$ zone extending over a 200-by-200-km region, with little shallow slip north of $38.8^{\circ} \mathrm{N}$. They find no clear evidence of significant seismic radiation after $150 \mathrm{~s}$ from the rupture onset.
The seismic, geodetic, and tsunami evidence for the 2011 Tohoku rupture extending out to the Japan trench prompted Kozdon and Dunham (2013) to explore 2D dynamic rupture models for which the shallow region of the megathrust has the commonly assumed velocity-strengthening material. They find that large ruptures that nucleate in regions of velocityweakening material readily penetrate tens of kilometers into regions with velocity-strengthening friction, allowing rupture to reach the trench. The occurrence of the 1896 tsunami earthquake in the shallow megathrust north of the 2011 rupture zone suggests that failure of the very shallow fault can occur even without being driven by strong deeper slip as in the case of the 2011 event. Other mechanisms such as thermal pressurization, anelastic deformation of the wedge, or transition in frictional behavior at high-slip velocities have been invoked to explain the 2011 Tohoku rupture extending to the trench, but it is not clear that special physical processes are needed to account for the 2011 rupture. The fact remains that most welldocumented great ruptures do not appear to have ruptured to the trench; some activate subsidiary ruptures on splay faults or rupture simply arrests on the shallow megathrust.

The diverse regional ground-motion recordings allow comparisons of various dynamic and static measurements to be made. Wang et al. (2013) use regional strong-motion records to derive the static displacements of the 2011 Tohoku earthquake, which are then used to estimate the coseismicslip distribution. They consider various data sets including GPS, ocean-bottom GPS, K-NET and KiK-net stations, and show that the slip models from the KiK-net borehole data are similar to the GPS-based model. It is suggested that joint use of strong-motion and GPS data could increase the station coverage for source inversions in general. They also compare the time series of displacement and velocity derived from the strong-motion data and the nearby GPS data by integrating and differentiating, respectively, and show that the two data sets are complementary to each other. Huang et al. (2013) address the estimation of ground displacement by double integration of acceleration recordings, demonstrating that the semi-automated empirical-mode-decomposition (EMD) method can provide acceleration baseline corrections, which improve agreement with GPS displacement histories. The EMD method process is effectively a filter bank of overlapping band-pass filters that decomposes the digital signal into several intrinsic mode functions.

Although full-waveform inversion of short-period seismic signals for rupture history of the Tohoku earthquake is not viable due to limited knowledge of propagation effects and rupture-process formulation, the high-quality strongmotion and short-period network data allow determination of regions of strong radiation on the megathrust to be resolved. Nakahara (2013) inverts 27 envelopes of high-frequency $S$-wave energy in three frequency bands from $1-8 \mathrm{~Hz}$ to determine source radiation from a 40-subfault model of the megathrust with eight source-time windows. The use of envelopes allows the coherent bursts of short-period radiation to be analyzed without requiring full knowledge of the 
scattering properties of the medium and details of the source dynamics. An overall rupture velocity of $2.5 \mathrm{~km} / \mathrm{s}$ is inferred along with $\sim 8$-s durations of high-frequency radiation from the subfaults. Two episodes of radiation are detected for the deeper subfaults off the Miyagi coastline, compatible with two intervals of longer period radiation from this part of the fault resolved in some geodetic and teleseismic finite-fault inversions. The primary high-frequency radiation is from down-dip of the hypocenter, with relatively little short-period energy radiated from the large-slip region extending up-dip from the hypocenter to the trench.

Five discrete regions of strong-motion-generating slip on the megathrust were located by Kurahasi and Irikura (2013) using a wave-packet-semblance analysis applied to K-NET, KiK-net, and Onagawa Nuclear Power Plant recordings in the passband $0.15-10 \mathrm{~Hz}$. The localized regions are located west of the hypocenter and along the down-dip edge of the main rupture zone and are distributed from the middle Sanriku-oki region to offshore Ibaraki Prefecture. The spatial distribution of short-period sources is generally compatible with that inferred from backprojections of teleseismic data near $1 \mathrm{~Hz}$. A stochastic finite-fault simulation was used to model average response spectra by Ghofrani et al. (2013). They examined several rupture-process models, finding that a multiple-event model with five strong-motion-generation areas that have random slip is able to favorably match both short- and long-period spectral amplitudes.

Frankel (2013) uses hr-GPS and strong-motion data to analyze the source-time properties of the 2011 Tohoku earthquake. This analysis yields three major subevents of the 2011 earthquake with individual magnitudes of 8.5, 9.0, and 8.0. He estimates $65 \mathrm{~m}$ of slip near the trench axis in the second subevent. The final subevent, located in the down-dip and southern region of the megathrust, was a high-stress-drop event that radiated more high frequencies than the other two subevents.

The nonuniform radiation of high-frequency seismic waves from the megathrust fault during the 2011 Tohoku earthquake motivated Ye et al. (2013) to examine the seismic radiation from other large earthquakes on and near the plate boundary around the 2011 rupture zone. Regional strongmotion data from the K-NET and KiK-net facilities and Hi-net stations were used to characterize variations in ground shaking for frequencies up to $10 \mathrm{~Hz}$ for $M_{\mathrm{w}} 6.0-7.6$ earthquakes on the megathrust and within the Pacific plate in the outer rise and below the Japan coast. Events near the coast systematically produce stronger shaking at high frequencies at comparable distances relative to events farther offshore on the megathrust, with particularly strong shaking from intraplate events below the megathrust. This is accounted for by a combination of lower attenuation on the paths and enriched high-frequency-source radiation down-dip. Empirical Green's function analysis is used to quantify the sourceradiation differences, demonstrating a general tendency of increasing short-period seismic radiation from deeper inter- plate events as well as for intraplate events. This behavior is useful to recognize for seismic-shaking-hazard assessments.

Dawood and Rodriguez-Marek (2013) develop a method to include variable path effects into ground-motion prediction equations. Attenuation rates are estimated using downhole recordings of 117 aftershocks at KiK-net stations. Path terms are computed for strong and weak ground motion and some correlation between these values is identified. Additionally, they demonstrate that there is higher attenuation in volcanic regions than in areas without volcanoes.

Near-surface site effects contribute significant variability to high-frequency ground shaking, which complicates isolation of source effects. Santisi d'Avila et al. (2013) examines strong ground motion amplification associated with the shallow soil-rock near-surface structure using a 1D threecomponent geomechanical model. A 3D nonlinear constituitive relation for dry soil is combined with a multisurface cyclic plasticity model to compute ground motions at four alluvial sites with a finite-element scheme.

The massive tsunami generated by the 2011 Tohoku earthquake was recorded by an unprecedented number of deep-ocean and coastal tsunami buoys, ocean-bottom pressure gauges, GPS wave gauges, wave and tide gauges, and extensive measurement of runup and inundation along the coasts of northeastern Honshu and southern Hokkaido. The slow propagation of tsunami waves relative to seismic waves provides heightened sensitivity to rupture finiteness, although the relatively long wavelengths involved suppress sensitivity to details of the slip distribution.

A unique observation of the tsunami from the 2011 Tohoku earthquake was recorded on a spring gravity meter on White Island in New Zealand. Using a hydrodynamic model of the tsunami and calculating the gravity response, Jolly et al. (2013) demonstrates that the observed gravity signal arises from water-mass changes during the tsunami. The authors indicate that gravity measurements of tsunamis can serve two functions. One, to gain a better understanding of the Earth's interior from gravity oscillations of a much different period than the normal diurnal tidal response and two, to provide an integrative measurement of the tsunami over a wide area for calibrating tsunami models.

The slip distribution of offshore earthquakes can be constrained using ocean-based time-series measurements of the resulting tsunami. Satake et al. (2013) use tsunami waveforms recorded on bottom-pressure and GPS instruments, as well as coastal wave and tide gauges to invert for the spatial and temporal slip distribution for a 55-subfault rupture model with five source-time intervals. Their slip model has two dominant features: a region with about 25-m slip in the central portion of the megathrust offshore of Miyagi Prefecture, and a near-trench region with slip as large as $69 \mathrm{~m}$ extending along the megathrust over a length of $400 \mathrm{~km}$. They infer that the deeper central megathrust region of slip is responsible for the initial tsunami waves and is in a similar location to the 869 Jogan earthquake. The deep slip associated with the 2011 Tohoku earthquake alone can reproduce the distribu- 
tion of deposits associated with the Jogan earthquake on the Sendai Plain. The later shallow slip appears to explain the very large tsunami-runup heights and tide-gauge amplitudes along the northern Sanriku coast. Finally, they find that the height of the tsunami that struck the Fukushima nuclear power station (15-m runup) resulted from the combination of deep and shallow rupture along the plate interface, which had not been accounted for in previous hazard assessments. The tsunami rupture model suggests a longer rupture process than inferred from seismic and hr-GPS inversions, with strong slip near the trench $180 \mathrm{~s}$ after initiation and northward extension of the slip along the 1896 source region to about $40^{\circ} \mathrm{N}$ persisting to about $270 \mathrm{~s}$. It is unclear how to reconcile this long duration estimate with other observations.

Yamazaki et al. (2013) sought self-consistent models of the rupture process compatible with teleseismic $P$ waves and regional tsunami waveforms, and then computed long-term standing edge wave patterns along the continental margin from Chiba to Hokkaido. They also characterize the tsunami source as having two dominant wave components from seafloor uplift under the central megathrust and near the trench that govern the character of the early tsunami waveforms. The constructive interference of standing edge waves accounts for persistent wave motions and delayed peak surges. It appears that much of the offshore buoy data can be reconciled with rupture models compatible with seismic and geodetic inversions with about 150-s rupture duration.

MacInnes et al. (2013) adopt a wide variety of source models for tsunami simulations of the 2011 Tohoku earthquake, using the same numerical method and bathymetric and topographic data for all the initial conditions. Simulated tsunami waveforms at DART buoys and tsunami heights along the Sanriku coast are compared with the observed and field-survey data in order to compare the source models. Tsunami-inundation computations with high-resolution grids are performed for five representative places from the Sendai Plain to Taro in Miyako City, and histograms of the ratios of simulated inundation heights over the actual measurements are analyzed.

Maeda et al. (2013) perform a large-scale numerical simulation (up to a maximum frequency of $0.5 \mathrm{~Hz}$ ) of the seismic motion, coseismic deformation, and tsunami, utilizing the massively parallel $\mathrm{K}$ computer, and the 3D finitedifference method based on the tsunami-coupled equation of motion they previously proposed. They argue for the necessity of the simultaneous simulation to explain the complex signals observed by the ocean-bottom pressure gauges, which contain effects of seismic/oceanic acoustic waves and tsunami. The snapshots of the computed strong motion and peak ground velocity are compared with observations, and effects of the water layer are discussed for the displacement fields on land. Snapshots of coseismic deformation and tsunami propagation are also presented.

Whereas tsunami runup and maximum tsunami amplitude are the conventional metrics for indicating the severity of a tsunami, these values often do not accurately represent the impact of a tsunami on the natural and built environment. Using damage and impact data from both the 2004 Indian Ocean and 2011 Tohoku tsunamis, Lekkas et al. (2013) develop a new 12-grade, integrated tsunami-intensity scale: ITIS-2012. The scale is based on six measurable criteria, such as the impact on infrastructure, impact on moving objects (e.g., ships, cars, or buildings), morphological alterations, and so on. The new intensity scale is amenable to microzonation of damage and can provide better damage assessment in the aftermath of a tsunami.

The persistence of Pacific-wide tsunami coda for up to five days after the 2011 Tohoku earthquake was explored by Saito et al. (2013) using procedures similar to those for seismic-coda decay. The average tsunami-coda-decay time scale is $\sim 24 \mathrm{hr}$, but large-amplitude tsunami arrivals were observed in Japan after an elapse time of about $48 \mathrm{hr}$ corresponding to the round-trip travel time to Chile. Inclusion of a bottom friction coefficient of $10^{-5}$ allows the tsunami-coda amplitude decay to be matched with global simulations for lapse times as long as $100 \mathrm{hr}$. Both scattering and intrinsic energy loss influence the tsunami-coda decay for large lapse times after $60 \mathrm{hr}$.

Widespread aftershock activity was induced in the eastern half of Honshu by the 2011 Tohoku earthquake, with unexpected activity in some regions, such as beneath the border between Fukushima and Ibaraki prefectures, which had previously had a low level of background seismicity. This region experienced a swarm of shallow normal faulting earthquakes. Lin et al. (2013) study meso- and microstructural deformation characteristics of the fault-zone rocks of the 11 April $2011 M_{\mathrm{w}}$ 6.6 Fukushima earthquake near Iwaki City, located $250 \mathrm{~km}$ southwest of the 2011 Tohoku earthquake epicenter. This aftershock involved subparallel 15-23-km-long surface ruptures on the pre-existing Shionohira (Itozawa West), Itozawa East, and Yunodake normal faults. The fault cores include narrow fault-gouge zones of $<10 \mathrm{~cm}$ in width, breccia zones of $<50 \mathrm{~cm}$ in width, and damage zones of 550-m width of cataclastic rocks. Toda and Tsutsumi (2013) estimate that maximum vertical offset on the Yunodake fault is $\sim 0.8 \mathrm{~m}$, whereas that on the Itozawa West fault is $\sim 2.1 \mathrm{~m}$, with it appearing that both ruptures occurred simultaneously. Trench excavation across the Itozawa fault indicates an earlier rupture more than 12,620 years ago and no failure during the 869 Jogan earthquake. Fukushima et al. (2013) examine the coseismic-displacement field for the 11 April 2011 event using InSAR images, estimating that the faults $\operatorname{dip} 60^{\circ}-70^{\circ}$ westward at shallow depth, with slip on several fault surfaces extending from the surface down to $10-12 \mathrm{~km}$.

Padhy et al. (2013) examined space-time changes in $S$-wave coda attenuation in the broad region around the 2011 rupture, finding modest increases (10\%-16\%) in attenuation for $1.25-3.5-\mathrm{Hz}$ signals on some paths near the rupture zone to stations in northern Honshu. The spatial distribution of the attenuation changes extends along the rupture zone near the Honshu coastline, and is attributed to microcracking from stress changes around the rupture zone during the mainshock. 
The strong shaking produced by the earthquake generated about 3500 landslides in eastern Honshu, as examined by Wartman et al. (2013). They find that about $80 \%$ of the landslides occurred in Quaternary soil and Neogene rock units, with relatively few in pre-Neogene rocks. There is not a strong correlation between landslide intensity and ground motion recorded by regional seismic arrays, indicating strong influence of the geologic unit, and the intensity of landsliding was low overall compared to other recent seismic events in Japan.

The 2011 Tohoku earthquake had a global reach, generating a Pacific-wide tsunami, producing seismic vibrations throughout the planet, perturbing the ionosphere, and redistributing enough mass to affect the planet's rotation. As one of a number of recent great earthquakes to strike around the world (since 2004 the rate of global shallow earthquakes with $M_{\mathrm{w}} \geq 8.0$ is over 2.5 times the average rate for such events since 1900), many questions arise about long-range interactions between such events.

van der Elst et al. (2013) examine the International Seismological Centre (ISC), USGS Preliminary Determination of Epicenters (PDE), and Japanese Meterological Agency (JMA) catalogs to evaluate whether a causal connection can be established among the 16 great earthquakes $\left(M_{\mathrm{w}}>8\right)$ around the world from 1998 to 2011, in terms of direct effect on local seismicity rates in regions of subsequent or prior great earthquake ruptures. This effectively tests the notion of dynamic activation of faulting in remote locations that over time culminates in delayed activated large events. Although some events appear to have remotely triggered faulting in the vicinity of later large events, the tendency for this to occur is quite weak and robust detection of rate changes depends on the catalog-completeness level. For example, the 25 September 2003 Tokachi-oki $\left(M_{\mathrm{w}} 8.3\right)$ earthquake activated an earthquake sequence within the future 2011 Tohoku rupture zone, but this is most evident in the JMA catalog, which has a low local magnitude threshold. Improvement in catalog completeness down to magnitude 3.5 locally or 2.0 regionally is needed to robustly detect triggered seismicity-rate changes. The overall rate increase for great earthquakes globally has not been accompanied by corresponding rate increase of lower magnitude events as might be expected for strong long-range causal interactions.

The Tohoku earthquake and its larger foreshocks and aftershocks produced oscillatory changes in groundwater levels $1500 \mathrm{~km}$ from the epicenter on Jeju Island, $140 \mathrm{~km}$ south of the mainland of Korea, as discussed by Lee et al. (2013). The groundwater conditions remained unstable for 5-7 days after the mainshock.

Chao et al. (2013) use the 2011 Tohoku earthquake as a source to study triggered tectonic tremor. They search for triggered tremor in all the locations where tectonic tremor (triggered or ambient) has previously been observed. They identify tremor in many regions, including in 8 of the 12 regions where tremor has been observed previously. The data reveal a relationship between the strength of triggered tremors and the strength of shaking from the earthquake at the same location. Analysis of the stresses associated with the surface waves of the Tohoku earthquake indicates that the combination of stresses from the Love and Rayleigh waves is responsible for the triggering, and not the Love or Rayleigh waves individually.

The long reach of the 2011 Tohoku earthquake effects is demonstrated by the investigation by Hill et al. (2013) of tectonic tremor triggered and modulated by $S, S S$, Love, and Rayleigh waves near Parkfield, California, about $8200 \mathrm{~km}$ from the source. The tremor was located 20 - to $30-\mathrm{km}$ deep on the San Andreas fault at sites $30 \mathrm{~km}$ northwest and 10$40 \mathrm{~km}$ southeast of Parkfield, in regions that have ongoing background-tremor activity. Dynamic stresses acting parallel to the strike with amplitudes from 2 to $10 \mathrm{kPa}$ appear to be the primary triggering stresses activating tremor during the passage of the shear and Love waves. The Rayleigh waves produce much weaker strike-parallel stresses of $\sim 0.5 \mathrm{kPa}$, but induce large tremor bursts.

The great 11 March 2011 Tohoku earthquake will continue to be the subject of many seismological, geodetic, and tsunami investigations as a result of its great societal impact and scientific importance. This special issue acknowledges both the prodigious power of nature exemplified by this event and the tragic losses that resulted, with a hope that scientific understanding of the event will guide future efforts to mitigate the impacts of these rare, extraordinary earthquakes.

\section{Data and Resources}

No data were used in this paper.

\section{Acknowledgments}

This special issue could not have been prepared without the generous contribution of many external reviewers and the encouragement of D. Doser.

\section{References}

Chao, K., Z. Peng, H. Gonzalez-Huizar, C. Aiken, B. Enescu, H. Kao, A. A. Velasco, K. Obara, and T. Matsuzawa (2013). A global search for triggered tremor following the $2011 M_{\mathrm{w}} 9.0$ Tohoku earthquake, Bull. Seismol. Soc. Am. 103, no. 2B, 1551-1571, doi: 10.1785/0120120171.

Dawood, H. M., and A. Rodriguez-Marek (2013). A method for including path effects in ground-motion prediction equations: An example using the $M_{\mathrm{w}} 9.0$ Tohoku earthquake aftershocks, Bull. Seismol. Soc. Am. 103, no. 2B, 1360-1372, doi: 10.1785/0120120125.

Frankel, A. (2013). Rupture history of the 2011 M 9 Tohoku Japan earthquake determined from strong-motion and high-rate GPS recordings: Subevents radiating energy in different frequency bands, Bull. Seismol. Soc. Am. 103, no. 2B, 1290-1306, doi: 10.1785/0120120148.

Fukushima, Y., Y. Takada, and M. Hashimoto (2013). Complex ruptures of the 11 April $2011 M_{\mathrm{w}} 6.6$ Iwaki earthquake triggered by the $11 \mathrm{March}$ $2011 M_{\mathrm{w}} 9.0$ Tohoku earthquake, Japan, Bull. Seismol. Soc. Am. 103, no. 2B, 1572-1583, doi: 10.1785/0120120140.

Ghofrani, H., G. M. Atkinson, K. Goda, and K. Assatourians (2013). Stochastic finite-fault simulations of the 2011 Tohoku, Japan, earthquake, Bull. Seismol. Soc. Am. 103, no. 2B, 1307-1320, doi: 10.1785/ 0120120228.

Hill, D. P., Z. Peng, D. R. Shelly, and C. Aiken (2013). S-wave triggering of tremor beneath the Parkfield, California, section of the San Andreas fault 
by the 2011 Tohoku, Japan, earthquake: Observations and theory, Bull. Seismol. Soc. Am. 103, no. 2B, 1541-1550, doi: 10.1785/0120120114.

Huang, J.-Y., K.-L. Wen, X.-J. Li, J.-J. Xie, C.-T. Chen, and S.-C. Su (2013). Coseismic deformation time history calculated from acceleration records using an EMD-derived baseline correction scheme: A new approach validated for the 2011 Tohoku earthquake, Bull. Seismol. Soc. Am. 103, no. 2B, 1321-1335, doi: 10.1785/0120120278.

Jolly, A. D., W. Power, N. Fournier, and X. Wang (2013). Capturing transient mass changes for the 2011 Tohoku tsunami on a spring gravity meter, Bull. Seismol. Soc. Am. 103, no. 2B, 1622-1627, doi: 10.1785/ 0120120104.

Kagan, Y. Y., and D. D. Jackson (2013). Tohoku earthquake: A surprise? Bull. Seismol. Soc. Am. 103, no. 2b, 1181-1194, doi: 10.1785/0120120110

Kawamura, M., Y.-H. Wu, T. Kudo, and C.-c. Chen (2013). Precursory migration of anomalous seismic activity revealed by the pattern informatics method: A case study of the 2011 Tohoku earthquake, Japan, Bull. Seismol. Soc. Am. 103, no. 2B, 1171-1180, doi: 10.1785/0120120094.

Kozdon, J. E., and E. M. Dunham (2013). Rupture to the trench: Dynamic rupture simulations of the 11 March 2011 Tohoku earthquake, Bull. Seismol. Soc. Am. 103, no. 2B, 1275-1289, doi: 10.1785/ 0120120136.

Kubo, H., and Y. Kakehi (2013). Source process of the 2011 Tohoku earthquake estimated from the joint inversion of teleseismic body waves and geodetic data including seafloor observation data: Source model with enhanced reliability by using objectively determined inversion settings, Bull. Seismol. Soc. Am. 103, no. 2B, 1195-1220, doi: 10.1785/0120120113.

Kurahashi, S., and K. Irikura (2013). Short-period source model of the 2011 Tohoku earthquake, Bull. Seismol. Soc. Am. 103, no. 2B, 1373-1393, doi: 10.1785/0120120157

Lee, S.-H., K. Ha, J. S. Shin, K.-S. Ko, and S.-Y. Hamm (2013). Successive groundwater level changes in relation to the $M 9.0$ Tohoku earthquake on Jeju island, Bull. Seismol. Soc. Am. 103, no. 2B, 1614-1621, doi: $10.1785 / 0120120054$

Lekkas, E. L., E. Andreadakis, I. Kostaki, and E. Kapourani (2013). A proposal for a new integrated tsunami intensity scale (ITIS-2012), Bull. Seismol. Soc. Am. 103, no. 2B, 1493-1502, doi: 10.1785/0120120099.

Lin, A., S. Toda, G. Rao, S. Tsuchihashi, and B. Yan (2013). Structural analysis of coseismic normal fault zones of the $2011 M_{\mathrm{w}} 6.6$ Fukushima earthquake, Northeast Japan, Bull. Seismol. Soc. Am. 103, no. 2B, 1603-1613, doi: 10.1785/0120120111.

MacInnes, B. T., A. R. Gusman, R. J. LeVeque, and Y. Tanioka (2013) Comparison of earthquake source models for the 2011 Tohoku event using tsunami simulations and near-field observations, Bull. Seismol. Soc. Am. 103, no. 2B, 1256-1274, doi: 10.1785/0120120121.

Maeda, T., T. Furumura, S. Noguchi, S. Takemura, S. Sakai, M. Shinohara, K. Iwai, and S.-J. Lee (2013). Seismic- and tsunami-wave propagation of the 2011 Off the Pacific Coast of Tohoku Earthquake as inferred from the tsunami-coupled finite-difference simulation, Bull. Seismol. Soc. Am. 103, no. 2B, 1456-1472, doi: 10.1785/0120120118.

Nakahara, H. (2013). Envelope inversion analysis for high-frequency seismic energy radiation from the $2011 M_{\mathrm{w}} 9.0$ off the Pacific coast of Tohoku earthquake, Bull. Seismol. Soc. Am. 103, no. 2B, 13481359, doi: 10.1785/0120120155.

Padhy, S., S. Takemura, T. Takemoto, T. Maeda, and T. Furumura (2013). Spatial and temporal variations in coda attenuation associated with the 2011 off the Pacific coast of Tohoku, Japan $\left(M_{\mathrm{w}} 9\right)$ earthquake, Bull. Seismol. Soc. Am. 103, no. 2B, 1411-1428, doi: 10.1785/0120120026.

Saito, T., D. Inazu, S. Tanaka, and T. Miyoshi (2013). Tsunami coda across the Pacific Ocean following the 2011 Tohoku-Oki earthquake, Bull. Seismol. Soc. Am. 103, no. 2B, 1429-1443, doi: 10.1785/0120120183.

Santisi d'Avila, M. P., J.-F. Semblat, and L. Lenti (2013). Strong ground motion in the 2011 Tohoku earthquake: A one-directional three-component modeling, Bull. Seismol. Soc. Am. 103, no. 2B, 1394-1410, doi: 10.1785/0120120208

Satake, K., Y. Fujii, T. Harada, and Y. Namegaya (2013). Time and space distribution of coseismic slip of the 2011 Tohoku earthquake as in- ferred from tsunami waveform data, Bull. Seismol. Soc. Am. 103, no. 2B, 1473-1492, doi: 10.1785/0120120122.

Toda, S, and H. Tsutsumi (2013). Simultaneous reactivation of two, subparallel, inland normal faults during the $M_{\mathrm{w}} 6.611$ April 2011 Iwaki earthquake triggered by the $M_{\mathrm{w}} 9.0$ Tohoku-oki, Japan, earthquake, Bull. Seismol. Soc. Am. 103, no. 2B, 1584-1602, doi: 10.1785/0120120281.

van der Elst, N. J., E. E. Brodsky, and T. Lay (2013). Remote triggering not evident near epicenters of impending great earthquakes, Bull. Seismol. Soc. Am. 103, no. 2B, 1522-1540, doi: 10.1785/0120120126.

Wang, R., S. Parolai, M. Ge, M. Jin, T. R. Walter, and J. Zschau (2013). The $2011 M_{\mathrm{w}} 9.0$ Tohoku earthquake: Comparison of GPS and strong-motion data, Bull. Seismol. Soc. Am. 103, no. 2B, 1336-1347, doi: 10.1785/ 0120110264.

Wartman, J., L. Dunham, B. Tiwari, and D. Pradel (2013). Landslides in eastern Honshu induced by the 2011 Tohoku earthquake, Bull. Seismol. Soc. Am. 103, no. 2B, 1503-1521, doi: 10.1785/0120120128.

Yamazaki, Y., K. F. Cheung, and T. Lay (2013). Modeling of the 2011 Tohoku near-field tsunami from finite-fault inversion of seismic waves, Bull. Seismol. Soc. Am. 103, no. 2B, 1444-1455, doi: 10.1785/0120120103.

Ye, L., T. Lay, and H. Kanamori (2013). Ground shaking and seismic source spectra for large earthquakes around the megathrust fault offshore of northeastern Honshu, Japan, Bull. Seismol. Soc. Am. 103, no. 2B, 1221-1241, doi: 10.1785/0120120115.

Yue, H., and T. Lay (2013). Source rupture models for the $M_{\mathrm{w}} 9.02011$ Tohoku earthquake from joint inversions of high-rate geodetic and seismic data, Bull. Seismol. Soc. Am. 103, no. 2B, 1242-1255, doi: 10.1785/0120120119.

Department of Earth and Planetary Sciences

University of California Santa Cruz

1156 High Street

Santa Cruz, California 95064

(T.L.)

International Institute of Seismology and Earthquake Engineering Building Research Institute

1 Tachihara, Tsukuba

Ibaraki 305-0802, Japan (Y.F.)

U.S. Geological Survey

345 Middlefield Rd.

Menlo Park, California 94025

(E.G., J.R.)

Earthquake Research Institute

University of Tokyo

1-1-1, Yayoi

Bunkyo-ku, Tokyo

113-0032 Japan

(K.K.)

Disaster Mitigation Research Center

Nagoya University

Furo-cho, Chikusa-ku

Nagoya 464-8601, Japan

(T.S.)

Seismological Laboratory

California Institute of Technology

252-21 Pasadena, California 91125

(M.S.)

Manuscript received 1 January 2013 